\title{
A Study on the Teaching Methods of Improving Students' Oral English
}

\author{
Xiaoqing Qian \\ Department of English, Zhenjiang Watercraft College, Zhenjiang, China \\ Email: qianxiaoqing88@hotmail.com
}

\begin{abstract}
Nowadays, with the development of the international relationship among countries, learning English, especially the oral English is playing a more and more important role in the world. After China's entry into the WTO, China has paid more attention to the oral English teaching in some colleges, which is not only the need of current quality education but also a revolution of the foreign language teaching. How to help undergraduates to improve their oral English becomes a big challenge in China. As we know, language is a significant communication tool for all the people. However, there are still some problems today about the oral English. This thesis will discuss some main factors affecting oral English, followed by exposing some factors including the lack of context, cultural factors, and language anxiety and so on. Then some necessary countermeasures of improving oral English will be put forward, which includes the methods of strengthening the teaching of English listening and speaking, the imitation, the repetition and the teaching environment. More importantly, it is necessary for students to find out disadvantages of oral English in time and then correct them quickly. Only in this way, students who are learning oral English can learn it well so that they can communicate to foreigners fluently.
\end{abstract}

Index Terms —oral English, improvement, relative factors, countermeasures

\section{INTRODUCTION}

It is acknowledged that Chinese students start to learn English from the early year of primary school. However, a confusing problem is how to improve students' oral English very well. The students who have learned thousands of words until now still cannot speak English fluently; even some of them can not open their mouths to speak English. This phenomenon has existed in China for many years, which is not neglected by some educational institutions, teachers or other scholars. This negative situation of oral English learning is caused by many inevitable reasons but luckily, it will be corrected in time as long as we can find out the reasons and take measures to solve these problems. It is necessary to study these problems from the perspective of students and teachers. Students should realize their own problems including the shyness to speak, the anxiety, the inner going character and other mental factors. Teachers should realize that whether the teaching environment meets the teaching needs or not. It is imperative to consider that whether the role of students has been into full played.

\section{MAIN FACTORS AfFECTING ORAL ENGLISH}

Learning a language is not easy, especially the oral English. It is a truth in China that thousands of students can not speak fluent English although they have learned it for many years. So here some main factors affecting the oral English will be discussed, followed by exposing some factors including the lack of target language learning environment, cultural conflict, the language anxiety as well as the rooted habit of "inert".

\section{A. The Lack of Target Language Learning Environment}

If a person stays in the foreign countries, he or she will practice their oral English in a short time, maybe just several months. That is why a majority of college students choose to study abroad. However, domestic students cannot own this perfect target language learning environment, which is an important factor affecting their oral English. In class, English teachers are mostly native Chinese speakers who have they can hardly speak as standard as native foreigners Students cannot learn a Standard English. In China, there are still some students cannot afford to study in the target language country. Even in some colleges, there are no foreign teachers can communicate with them in their daily life just like a pair of friends. It is so difficult for them to find out a native speaker to practice every day.

\section{B. The Special Character of Chinese}

In the long history of China, Chinese people are typically self-conscious when speaking a language. They are so shy to open their mouth, especially when making mistakes in public in case all the people around would laugh at them loudly for fear of being ridiculed or losing face, people are not willing to communicate in target language. This made them unwilling to communicate in target language for fear of being ridiculed or losing face. Little by little, dumb English becomes the fatal factor for the English learners. When reading English, out of Chinese preference to be quiet, 
English learners like to read in silence instead of speaking aloud in public, which is also an obstacle to oral English learning.

\section{The Cultural Conflict}

The cultural conflict is a crucial factor influencing one's oral English, including the religion, the oral speaking habit, the privacy problem and festivals. For example, foreigners do not like to be asked some private questions such as" How much do you earn?" or "How old are you?". These questions are not boring but private to foreigners. However, Chinese people cannot avoid asking such kind of questions. Due to the culture differences sometimes the foreigners become angry while the Chinese begin to feel so bad and decide to stop learning English to avoid any trouble. Culture is the carrier of one country, which can not disappear gradually, so what people need to do is to adapt themselves to such kind of new culture and environment. Paying attention to the cultural difference, one can avoid making mistakes in their life.

\section{The Rooted Habit of "Inert"}

"Inert" here means "inactiveness" in the class. In the traditional teaching class, the teacher likes to ask students questions and the students should hand up to answer. However, some Chinese students are not active in class. When being asked, most of them lower down their heads and pretend not to hear what the teacher said. Therefore, they always miss this chance to stand up and say something in English, which is a better way to practice English. When groups of student are chosen to discuss something, they often reject it. Such kind of shyness has been rooted in the Chinese heart for a long time. What students need to do is to change their shyness and try to accept new challenges bravely in their life, which is an important factor affecting their mental quality to speak perfect English.

\section{E. The Language Anxiety}

Sometimes people who would have spoken perfect English, but they failed to open the mouth due to anxiousness. This bad mental quality is related to language learner's personality. It is because that this person often feels nervous when he or she is doing something. This affects their learning achievements in their life. If they can resist this kind of anxiety, perhaps they will speak English better. Sometimes they can achieve success, but the anxiety becomes a big barrier for them to overcome. Mentality is an important factor affecting one's oral English, if one has a strong and brave heart to learn English, when meeting difficulties, he or she will resist it and continue to do what they have done before. In people's daily life, there are some people who are afraid of speaking in public, which is an enemy to the progress. Thus, students should practice to speak in public with a brave heart. In China, there is a problem that schools or colleges pay little attention to the cultivation of oral English, as a result, few oral courses are conduct and little chance of practicing is provided to students, which is a significant problem for educational institutions to think about.

\section{COUNTERMEASURES TO IMPROVE ORAL ENGLISH}

English is playing a very important role in the world. More and more people put stress on English learning in order to adapt to the needs of social development. Nevertheless, how to communicate in English is also very important. Here some countermeasures to improve students' oral ability will be put forward.

\section{A. The Training of English Listening \& Speaking}

Speaking cannot be taught separately and it has to be combined with listening. When the students are listening, they can imitate the correct pronunciation and intonation. They also get much information to speak by listening. Learning English for Chinese students involves many aspects such as reading, writing, listening and speaking. It is said that if a person can do well in these four aspects, he or she will have a good master of English. In terms of oral English, listening and speaking are the first and foremost abilities. While there are some measures to strengthen the teaching of English listening and speaking. Listening is the basic of speaking. Chinese education institutions require the middle school, high school and colleges to take the listening into account and establish some courses about listening in universities. In the CET4, CET6 and TEM8 or other examines, listening comprehension is the essential section for students.

\section{a. Imitation}

Imitation is one of the best methods to improve oral English. In order to improve the listening ability, students can choose to listen to some tapes of English. Following English tapes and imitating sentences will be an effective way to improve pronunciation and intonation. By taking down what have been heard and imitated, English learners can accumulate more vocabulary and make a great progress. As a child can fast master the mother language, only by hearing and imitating a lot before speaking, one can for sure improve the oral English. New concept English is also a good choice to refer to. In addition, watching some English or American movies and imitate the speaking tone and speaking mode is a good method. In a word, imitation is conducive to the improvement of oral English.

\section{b. Repetition}

As the saying goes, "Practice makes perfect". Repetition is a good and effective way to improve oral English. For example, students can choose the book of Crazy English. According to the Crazy English advocates, one word or sentence can be practiced a hundred times before being perfect. By following the teacher and repeating a word repeatedly, one can easily speak out without any hesitation. Even though it is hard to be persistent, only sticking to the habit to practice, one can finally be excellent. Repetition is to keep doing the same thing repeatedly. Repeating some 
key sentences from the texts can improve students' ability of oral expression.

\section{B. Multi-angle in All Directions to Create a Foreign Language Environment}

Foreign language environment can help an English learning student a lot. This special environment can place the student into a "second motherland". Surrounded by foreigners everyday, people have to speak English in order to communicate with others. Therefore, it is necessary to have a foreign language environment. Some schools can establish English corners composed of native English speakers and foreign teachers where students can practice English by talking with each other. Even in some schools without English corner, it is a little difficult for Chinese students to practice English well. In addition, with the spread of the Internet, some domestic student can find foreigners online. Although Internet sometimes is an unreal world, it is a way to communicate in English. Students can introduce to foreigners what has happened in China and these foreigners can tell Chinese students what has happened in UK or US. Students can even go to some places full of foreigners, such as Beijing, Shanghai, and Shenzhen and so on. It is really a big environment to practice English.

\section{A Relaxed Teaching Environment}

Interest is the best teacher for students. Students like the comfortable and relaxed environment instead of the boring and annoying one. In terms of the teaching environment, first comes to the concrete environment. The classroom should be surrounded with the English cultural features. Students can write on the blackboard an English proverb or the English version of cards or pictures that can also be written in the English version to reinforce students to read. Second is about the abstract environment. The teachers should avoid using some traditional teaching methods--roll calling and question answering. Instead, teachers can arrange the courses through means of games. This is a so relaxed environment that students will not feel nervous or get pressure by being laughed at or making mistakes. The teacher should always encourage students more to speak English loudly and correctly.

\section{CONCRETE WAYS TO IMPROVE ENGLISH ORAL ABILITY}

Although there are some problems about the English oral ability, concrete ways to improve students' speaking English can be taken advantage of, including putting the main role of students into full play; improving students' sensitivity to cultural differences; attention to student's oral errors.

\section{A. The Main Role of Students into Full Play}

Students should be paid attention to by teachers. The teaching process is a mutual one between students and teachers. Students should be given more time and chances to practice their oral English. In order to help students improve their listening, speaking and overall communication ability, teachers should make students realize their dominant roles in class and make sure everything can be talked in English as much as possible. For instance, a discussion subject for students can be put forward. The rest of the time is left for them. Students can be divided into two groups, one is positive partner and the other is the negative partner. A fierce discussion in English can be read and the teacher aside will give some suggestions about pronunciation or tones. Meanwhile, the teacher can ask students to make a PPT to introduce anything interesting, which can also be regards as a process of practicing the oral English. Sometimes teachers can conduct some program of role-play activities for students to practice and speak English in a more meaningful way as a practical language.

Different students may meet different problems in class. If being nervous to open the mouth in public, one can improve confidence by delivering speeches as much as possible. The teacher should also give more chances to students to speak at class. Through training, if being bad in English words pronunciation, one should take a record or MP3 and listen to the native English speaker. In the class, a game about speaking the correct word can be created. The victory team will be given the prizes, which can promote students' confidence. If students have some difficulties in understanding the foreign culture, which make them feel shamed of making mistakes, then the teacher should find some books to read for them and then let them to retell the text. There are many examples cannot be told here one by one. In a word, it is necessary to find a way suitable for them.

\section{B. The Improvement of Students 'Sensitivity to Cultural Differences}

Just like what mentioned above, cultural differences are the key problem for the English learners. Without knowing a country's culture, no matter how good the oral English is, one can hardly avoid being laughed at by foreigners of the foolish words or behaviors. In order to avoid this situation, the schools and colleges should set up some courses about the cultural differences between China and other western countries. Students should be aware of their different religions, customs, culture, speaking mode and so on. Nowadays some educational channels also show different cultures in foreign countries. Students will be told what should be done and what can't be done in order not to break up the relations with foreigners. By reading some books or watching some programs about culture, students will have a clear understanding of the cultural differences. For example, "dragon" is the symbol of China, but stands for an evil to the western countries. Students can go to the library to find some books on the cross-culture and learned something. The educational institutes should conduct some course to help us understand more about the cross-culture. Student also can watch TV or listen to the video to get this information. If they have the opportunity to go abroad, they can experience 
different countries' culture well. But in our country, there are also lots of foreigners so that students can communicate with them about the cross-culture. Students need to take advantage of each resource which can improve and enhance their awareness of cross-culture. In a word, "Do in Rome as the Romans do"

\section{The Attention to Student's Oral Errors}

In this process of English oral learning, there are still some students cannot speak correct English, due to the less attention on the oral practice and negative attitude in English learning, especially to the pronunciation. For example, when a certain student is talking with a foreigner, he or she cannot say a correct word, which makes it difficult to understand what the meaning is. This is a bad phenomenon for an English learning. Therefore, when studying English, students should pay more attention to grammars. Besides, teachers need to correct errors and guide students how to express correctly. Some techniques should also be told when dealing with some confused words instead of just correcting their errors. It is quite different in the teaching process, which can encourage students to study the oral English to speak fluent English.

\section{Matters NeEd AtTEntion}

During the process of improving students' oral English, we still need to pay more attention to students' speaking quality, which is necessary for Chinese students. Besides, gestures, movements and facial expressions needed in class to enhance students' oral English.

\section{A. Paying Attention to the English Speaking Quality}

In the process of improving the oral English, there are also some problems need to be paid attention, especially English speaking quality. Students should focus on their pronunciation, vocabulary, and grammar. Great efforts should be made great efforts at pronunciation primarily in order to study oral English well. Students should pay more attention to the phonetic symbol learning. Phonetic symbol is the base of speaking. For example, the phonetics of $/ \theta /$ should be extremely noticed, which is a frequent phonetics in the western countries. Until now, some students cannot say "Thank you" correctly. The phonetics should be practiced by reading some words including this phonetics of $/ \theta /$, such as "tooth", "mouth" and so on. To improve students' oral English, students must practice more in liaison, weak reading, Plosive losing, accent, and so on. Some pronunciation is hard to pronounce in English. In order to solve the problems of pronunciation and intonation, some suitable training is necessary.

\section{B. Speaking English with Gestures, Movements and Facial Expressions}

Body language is a complement to verbal communication, in daily communication, people always value verbal communication but ignore the importance of non-verbal communication in message conveyance. Without gestures, our world will be static and colorless. "Eyes are the windows of the soul", the ever changing expressions in eyes reflects people's rich and colorful inner world. The face has been called an organ of emotion because we constantly read facial expressions to understand what others are feeling. When somebody is speaking perfect English, he or she will have to use some gestures, movements and facial expressions to enhance the spoken meanings. The gestures mainly mean the body gesture that can be shown through the parts of body such us the mouth, hands, head and legs, etc. When talking to a foreigner in English, one can use the body gestures to help the foreigner know the meanings he/she is expressing. Sometimes, facial expressions can tell the foreigner what exactly is talking about. Some scientific researches have suggested that certain gestures, movements and facial expressions can promote mutual communication in a more effective way. This is related to constrain of culture, customs or other things. For example, if a student goes to restaurant with a foreigner, the foreigner wants to eat some Chinese dishes, without knowing how to express, hands would be used to express ideas.

\section{Speaking English as Soon as Possible after Learning}

After learning one language, one should use it immediately and speaking it as much as possible. The short memory of human being requires people to use the language at once after learning. For example, if one watched an English film, then he or she should imitate and practice it in this short time. Through repeating imitations and speaking, what they have learned cannot be easily forgotten. Later in time, this short time memory can transfer into the long-term memory, so it is easier for students to remember their English language and speak it out anytime. So speaking English as soon as possible after learning is the basic to get the final command of this language. Chinese Confusion ever said that people need to review what they learned before, as long as one can review and practice, he or she will do it well. However, Chinese students are often loaded with heavy homework so that they have little time to review things or they are tired of reviewing. Thus, college should give students more time and space to learn and review to help them enhance their memorizing ability. College should carry out some contests for students to test their memorizing ability; the winner can be given the prize as an honor. Little by little, it will become easy for students to remember the knowledge.

\section{CONCLUSION}

After analyzing factors affecting the improvement of students' oral English, a conclusion is made. It is acknowledged 
that oral English is so significant in the teaching process today, so it is imperative to improve students' oral English.

Speaking is the most important skill of all. As a kind of language, English is used to communicate with each other. Therefore, the aim of learning English is to learn how to speak. With the development of the economy and society, the oral English is becoming more and more important. If the students want to speak well, it is required to master rich English language and insist on practicing. In addition, the speaking is a skill that can and should be developed in China if the students and the teachers can work hard together. The present paper explicates the importance of oral practice in the study of the English language from various angles. After exploring these factors affecting the oral English, some measures are suggested to solve this problem. Improving students' oral ability is not just completed in one day, which needs to be improved in a long time. Students' activeness should be provoked to enjoy the feeling of learning English. This is a necessary context for English learners. The educational institutions should make every effort to provide a good learning environment for students. Students should also be given a platform to improve oral English. "Practice makes perfect." with the consistent practice, as a communication tool, English will play a better role in the development of globalization.

There are two limitations in this thesis. Firstly, this research is only based on the author's observation and experience, which discusses how to develop the students' oral competence but ignores others factors like students' motivations and teachers' levels. Secondly, the thesis suggests and describes the methods in the oral English. More related research can be still carried on in the near future.

\section{REFERENCES}

[1] Benhu, Wu. (2002). English Learning Strategies. Anhui: Foreign Language Educational Press.

[2] Buchfield. (1992). The English Language. New York: Oxford University Press

[3] Littlewood, W. (2007). Communicative and Task-Based Language Teaching in East Asian Classrooms. Language Teaching. 40,243-249.

[4] Nunan, David.(2000). Designing Tasks for the Communicative Classroom. Beijing: Foreign Language Teaching and Research Press.

[5] Suping, Ding. (2000). Five Strategies in Creating Real-World Classroom Activity. Beijing: Foreign Language Teaching and Research Press.

[6] Smith F. (1978). Understanding Reading (2d ed). New York: Holt, Rinehart and Winston.

[7] Wilga M. Rivers \& Mary S. Temperley. (1978). A Practical Guide to the Teaching of English as a Second or Foreign Language. New York: Oxford University Press.

[8] Xueliang Gu, (1998). The Basic Technical Training in English Teaching. Hangzhou: Hangzhou University Press.

[9] Weir, C., O’Sullivan, B., and Horai, T. (2004). Exploring Difficulty in SpeakingT asks: An Intra-Task Perspective. IELTS Research Reports Volume 6. 6,181-191.

Xiaoqing Qian was born in Yiwu, Zhejiang Province, China in 1982. She received her B.A. degree in English language and literature from Zhejiang University of Commerce, China in 2005.

She is currently a lecturer in English Department, Watercraft College, Zhenjiang, China. Her research interests include teaching methods and second language acquisition. 